\title{
Las reclamaciones en materia de contratación pública en Navarra
}

\author{
José Francisco Alenza García \\ Profesor Titular de Derecho Administrativo \\ Universidad Pública de Navarra \\ jose.f.alenza@unavarra.es
}

\begin{abstract}
Resumen
La regulación de las reclamaciones en materia de contratación pública en Navarra se analiza desde su perspectiva estática y dinámica. En la estructura estática de la relación jurídica de la reclamación se estudian los sujetos de la relación (los reclamantes y la Junta de Contratación Pública) y el objeto de la misma, que son los actos de la contratación pública impugnable y los motivos que se pueden invocar.

En la estructura dinámica se estudia el procedimiento de reclamación: iniciación, medidas cautelares, actos de instrucción y terminación del procedimiento, con especial atención a los criterios y al contenido de la resolución.

Por último, se describen las diferencias principales que se pueden apreciar entre la regulación navarra y la estatal sobre las reclamaciones en materia de contratación pública.
\end{abstract}

Palabras clave

Contratos públicos, recursos especiales, Derecho público de Navarra.

\section{Public procurement claims in Navarre}

\begin{abstract}
The regulation of public procurement claims in Navarre is analysed from a static and a dynamic perspective. In the static structure of the legal relationship of the claim we look at the subjects of the relationship (the claimants and the Public Procurement Board) and the object of the claim, which are the challengeable public procurement acts and the reasons that can be given.

In the dynamic structure, we analyse the claims procedure: initiation, precautionary measures, pre-trial proceedings for examination and conclusion of the proceedings, with special emphasis on the criteria and content of the decision.

Lastly, we describe the main differences found between Navarre and State public procurement claims regulation.

Key words

Public contracts, special reviews, Navarre public law.
\end{abstract}




\section{LA ESPECIALIDAD DE LAS RECLAMACIONES EN MATERIA DE CONTRATACIÓN PÚBLICA EN NAVARRA}

\section{Una normativa pionera}

La creación en España de una vía especial de recurso administrativo sustitutivo de los recursos ordinarios se ha producido por impulso del Derecho comunitario europeo. Las denominadas Directivas de recursos establecieron unas exigencias mínimas para la instauración de un tipo de recurso especial -judicial o administrativo- en materia de contratación que garantizara la efectividad de la regulación comunitaria de los procedimientos de adjudicación de los contratos públicos¹.

Como es sabido, la legislación estatal se resistió, por entender que era innecesario, a introducir modificaciones tendentes a incorporar las medidas previstas en la normativa comunitaria, lo que supuso para España la condena por incumplimiento del Derecho comunitario². Posteriormente, la Ley 30/2007, de 30 de octubre, de Contratos del Sector Público introdujo el recurso especial en materia de contratación. A continuación, la Directiva 2007/66/CE modificó las Directivas de recursos y el legislador estatal realizó la transposición mediante la ley 34/2010, de 5 de agosto, modificando la LCSP y dando lugar a la reciente aprobación del Texto Refundido de la Ley de Contratos del Sector Público, mediante el Real Decreto Legislativo 3/2011, de 14 de noviembre (en adelante, TRLCSP)3.

Antes de la completa transposición estatal de las exigencias comunitarias, la legislación balear y la legislación navarra se adelantaron y establecieron un recurso ad-

1 Son la Directiva 89/665/CEE, de 21 de diciembre, y la Directiva 92/13/CEE del Consejo, de 25 de febrero. Sobre el contenido de estas Directivas me remito a Mestre Delgado, J. F. y Huergo Lora, A., "Contratos públicos: control de la adjudicación”, en el vol. col. Diccionario de Derecho Administrativo (Dir. S. Muñoz Machado) ed. lustel, Madrid, 2005, pp. 716-722, y la bibliografía citada en dicho trabajo.

2 SSTJCE de 15 de mayo de 2003 y 16 de octubre de 2003. Entre los numerosísimos comentarios a esta jurisprudencia véase García de Enterría, E., “El Tribunal de las Comunidades Europeas constata y censura dos graves quiebras de nuestro Derecho administrativo en materia de entes sujetos al Derecho público y a medidas cautelares contencioso-administrativas", REDA, núm. 119, 2003, pp. 473 y ss.

Posteriormente la STJCE de 3 de abril de 2088 volvió a condenar a España por incumplimiento de la Directiva de recursos. Sobre esta sentencia véase, entre otros, Vázquez Matilla, F. J., "Comentario a la STJCE de 3 de abril de 2008. La vulneración de la Directiva sobre recursos y su incidencia en la normativa sobre contratación administrativa en Navarra", Revista Jurídica de Navarra, núm. 45, 2008, pp. $149-181$.

3 Entre la abundantísima bibliografía sobre esta cuestión me remito a los siguientes trabajos: Razquin Lizarraga, J. A., "El sistema especial de recursos en la contratación pública tras la reforma de la Ley de Contratos del Sector Público”, Revista General de Derecho Administrativo, núm. 25 (2010); Gimeno Feliu, J. M., "La adjudicación de contratos en la LCSP y los mecanismos de control (el recurso especial)", en el vol. col. Estudios sobre la Ley de Contratos del Sector Público, (coord. J. Colás Tenas), 2009; pp. 197-246; y del mismo autor "El sistema de reclamaciones previsto en la Ley 31/2007, de 30 de octubre", Noticias de la Unión Europea, núm. 301, 2010, pp. 47-57; Moreno Molina, J. A., "Principios generales de la contratación pública, procedimientos de adjudicación y recurso especial en la nueva Ley estatal de contratos del sector público", Revista Jurídica de Navarra, núm. 45, 2008, pp. 45-73; y del mismo autor “La Ley 34/2010, de 5 de agosto, de modificación de la Ley de Contratos del Sector Público en materia de recursos y su incidencia en Castilla-La Mancha”, Revista Jurídica de Castilla-La Mancha, núm. 49, 2010, pp. 97-123; Tornos Mas, J., “Novedades en la regulación de los recursos en materia de contratos de las Administraciones Públicas”, Contratación Administrativa Práctica, núm. 59, 2006, pp. 45-60. 
ministrativo especial en materia de contratación pública cuya resolución se atribuye a un órgano distinto a la entidad contratante.

La Ley Foral 6/2006, de 9 de junio, de contratos públicos (LFCP, en adelante) regula las que denomina "reclamaciones en materia de contratación pública" en el Título II de su Libro III4. Las previsiones legales fueron objeto de desarrollo reglamentario mediante el Decreto Foral 236/2007, de 5 de noviembre, por el que se regula la Junta de Contratación Pública y los procedimientos y registros a su cargo (DFJCP, en adelante). Finalmente, cabe señalar que la regulación navarra se completa con la legislación de régimen local que contiene sus propias peculiaridades 5 .

La LFCP destaca en su exposición de motivos la novedad que supone la incorporación de la reclamación en materia de contratación pública como "un recurso administrativo de carácter potestativo y sustitutivo, con plazos muy breves de resolución, con el fin de cumplir el objetivo de dicha Directiva de crear medios de recurso eficaces y rápidos, especialmente en la fase en la que las infracciones aun pueden corregirse". Y, más adelante, explicita las finalidades de la reclamación en los siguientes términos:

“La reclamación, cuya regulación permite cumplir con los mandatos de la normativa comunitaria, es un instrumento necesario para dar plena efectividad a los preceptos recogidos en la Ley Foral, así como a los principios comunitarios europeos que la inspiran, de tal forma que se alcancen mayores niveles de transparencia y se abra la contratación pública a un mayor número de empresas, con los consiguientes ahorros de costes de los sujetos implicados en la misma".

Esta reclamación en materia de contratación pública ha sido caracterizada con las siguientes notas: recurso administrativo (en vía administrativa y no judicial) de carácter especial (doblemente especial por ir referido al ámbito concreto de la contratación pública y por referirse sólo a los actos de licitación y adjudicación), potestativo y sustitutivo del sistema ordinario de recursos, establecido con el doble objetivo de lograr la rapidez en su resolución y de que tenga eficacia suficiente para evitar la celebración de contratos litigiosos ${ }^{6}$.

Antes de entrar en el análisis detallado de estas características, me parece oportuno señalar algunos datos sobre la experiencia desarrollada en Navarra sobre estas reclamaciones contractuales en los últimos cinco años.

4 El primer estudio y más completo de esta regulación foral es el de Razquin Lizarraga, J. A., “Las reclamaciones y otras medidas de control en materia de contratación pública”, en el vol. col. Comentarios a la Ley Foral de Contratos Públicos (dir. J. C. Alli Aranguren), ed. Gobierno de Navarra, Pamplona, 2006, pp. 734-796.

5 Por razones de espacio no me ocuparé en este trabajo de las reclamaciones contractuales en el ámbito local. Para su conocimiento me remito al trabajo citado en la nota anterior.

6 Esta definición de la reclamación contractual (y la explicación del significado de sus términos) ha sido establecida por Razquin Lizarraga, J. A., "Las reclamaciones y otras medidas de control en materia de contratación pública", cit. pp. 764 y ss. 


\section{Datos sobre las reclamaciones contractuales en Navarra desde su creación}

Decía J. A. Razquin en su estudio de la regulación foral que, una vez aprobada ésta, el reto estaba en la implantación efectiva del sistema de reclamación y su practicabilidad. El sistema funcionará si ofrece garantías reales a los interesados de rapidez, imparcialidad, objetividad y eficacia, esto es, soluciones rápidas que logren evitar los contratos litigiosos?.

Han transcurrido ya cinco años y pueden ofrecerse unos datos sobre la actividad de la Junta de Contratación Pública en su faceta de órgano de resolución de las reclamaciones especiales en materia de contratación ${ }^{8}$. Desde finales de 2006 hasta el 1 de agosto de 2011 las resoluciones de la Junta de Contratación Pública de reclamaciones han sido 73, con la siguiente distribución anual:

\begin{tabular}{|c|c|c|c|c|c|c|c|}
\hline Año & $\mathbf{2 0 0 6}$ & $\mathbf{2 0 0 7}$ & $\mathbf{2 0 0 8}$ & $\mathbf{2 0 0 9}$ & $\mathbf{2 0 1 0}$ & $\mathbf{2 0 1 1}$ & TOTAL \\
\hline $\mathrm{N}^{\circ}$ reclamaciones & 3 & 6 & 13 & 16 & 17 & 18 & 73 \\
\hline
\end{tabular}

Como se puede apreciar, cada año el número de reclamaciones ha superado al del año anterior. Para un análisis completo habría que tener datos sobre los actos pre-contractuales que habían sido objeto de impugnación antes de la incorporación de la reclamación especial. En cualquier caso, lo que sí se puede afirmar es que el conocimiento de la vía especial de reclamación en materia contractual se ha ido incrementado cada año y, a lo que parece, ha ido ganando también la confianza de los interesados.

La clasificación por materias pone de relieve, sin embargo, que un gran número de reclamaciones no supera el trámite de admisión, quizá porque todavía no se conocen bien los requisitos especiales de la reclamación. Esta es la clasificación por materias:

Causas de inadmisión: 38

Entidades sometidas a la LFCP: 1 .

Prohibiciones de contratar: 2.

Exclusión de licitadores: 6 .

Publicidad de las licitaciones: 6 .

Exclusión de ofertas: 6.

Criterios de adjudicación: 8.

Valoración de las ofertas: 14.

Procedimiento de las reclamaciones: 7 .

7 Razquin Lizarraga, J. A., “Las reclamaciones y otras medidas de control en materia de contratación pública", cit. p. 796.

8 Tomo los datos ofrecidos por la propia Junta de Contratación Pública en el Portal de Contratación: http://www.navarra.es/home_es/Servicios/Portal+contrataciones/Utilidades/Informacion/Resoluciones/ 


\section{La relación jurídica como método para analizar las reclamaciones en materia de contratación pública}

La interposición de una reclamación en materia de contratación pública da lugar a una relación jurídica entre el reclamante y la Junta de Contración Pública. Parece propicio, por ello, analizar esta relación jurídica de reclamación mediante el empleo de la metodología de análisis relacional, de acuerdo con el modelo propuesto por Jaime Guasp ${ }^{9}$ y desarrollado en el ámbito jurídico-administrativo por González Navarro ${ }^{10}$.

Básicamente, este modelo de análisis relacional parte del estudio de la estructura estática de la relación jurídica, contemplando cada uno de sus elementos (sujetos, objeto y elemento conectivo o integrador) y se completa con el estudio del comportamiento y ciclo de vida de la relación -estructura dinámica-, distinguiendo al efecto las situaciones germinales de la relación, las situaciones de desarrollo y las situaciones terminales que ponen fin a la relación.

\section{ESTRUCTURA ESTÁTICA}

\section{Sujetos}

\subsection{La Junta de Contratación Pública como órgano de resolución de las reclamaciones}

\section{A) Naturaleza jurídica: órgano administrativo independiente, plurifuncional y especializado}

La normativa comunitaria deja abierto el carácter administrativo o judicial del procedimiento de recurso en materia contractual. La LFCP, al igual que hizo posteriormente la LCSP, ha optado por la configuración administrativa de las reclamaciones contractuales, al atribuir la resolución de las mismas a un órgano administrativo: la Junta de Contratación Pública.

Esta Junta de Contratación Pública queda adscrita al Departamento competente en materia de economía y se describe como "el órgano consultivo, asesor y de resolución en materia de contratación pública de las entidades sometidas a la presente Ley Foral, como órgano resolutorio común no sometido a instrucciones jerárquicas" (art. 208.1 LFCP).

Dos notas resultan de esta descripción: su carácter plurifuncional (órgano consultivo, asesor y de resolución) y su independencia funcional (no está sometido a

9 Guasp, J., Derecho, Madrid, 1971, especialmente páginas 127-174 (estructura estática) y 174-271 (estructura dinámica).

10 González Navarro, F., Derecho administrativo español, tomo I, ed. EUNSA, Pamplona, 1993, pp. 27-53. 
instrucciones jerárquicas) ${ }^{11}$. Ahora bien, más allá de esta proclamación no se establecen mayores garantías de esa independencia funcional a diferencia de lo que hace la legislación estatal al establecer el carácter independiente e inamovible de los miembros del Tribunal, determinar un largo plazo a su nombramiento (6 años) y limitar las causas por las que pueden ser removidos de sus puestos ${ }^{12}$.

Una tercera característica de la Junta resulta de su composición, pues sus miembros "deberán necesariamente tener especial preparación en materia de contratación pública” (art. 208.2 LFCP).

Estas tres características serán objeto de análisis en los siguientes apartados.

\section{B) Funciones de la Junta de Contratación Pública}

En cuanto órgano consultivo, asesor y de resolución, se asigna a la Junta de Contratación Pública una extensa lista de funciones con carácter abierto y que consta de las siguientes (art. 208.3)

“a) Informar y, en su caso, proponer las normas, medidas o instrucciones que incidan en los aspectos administrativos, técnicos y económicos del sistema de contratación.

b) Elaborar criterios y baremos de adjudicación que puedan servir de referencia a las distintas personas y entidades sometidas a la presente Ley Foral.

c) Informar a las personas y entidades sometidas a la presente Ley Foral y a las organizaciones empresariales y profesionales afectadas por la contratación pública sobre cuestiones relacionadas con dicha materia que se sometan a su consideración.

d) Proponer al Gobierno de Navarra la aprobación de modelos normalizados de documentos relativos a la preparación, adjudicación y modificación de los contratos.

e) Informar sobre la procedencia de no publicación del resultado de una licitación.

f) Centralizar la información estadística que se deba suministrar a la Junta Consultiva de Contratación Administrativa del Ministerio de Economía y Hacienda sobre los contratos que reglamentariamente se determinen, a efectos del cumplimiento de la normativa internacional.

11 En consonancia con este carácter el artículo 1.2 del DF precisa que "en el desarrollo de sus funciones tiene garantizada plena autonomía funcional para cumplir adecuadamente sus fines. En ningún caso responderá a instrucciones jerárquicas".

12 Artículo 41.1 TRLCSP.

13 El artículo 2 del DFJCP todavía añade otras funciones a la Junta o pormenoriza las establecidas 
g) Resolver los arbitrajes en materia de fijación de precios en los contratos de obras de la Administración.

h) Resolver las reclamaciones en materia de contratación pública”.

Quedan de esta manera pormenorizadas las funciones consultivas y asesoras de la Junta, mientras que su carácter resolutorio se refleja en la última de las funciones atribuidas.

Pero esta función de resolución -que es la que aquí interesa- ha provocado el cambio de la denominación tradicional de este órgano, antes denominado Junta Consultiva de Contratación. Ahora, al recibir esta nueva función de resolución desaparece de su denominación el calificativo "consultiva".

\section{C) Composición y funcionamiento}

Como ya se ha dicho, la LFCP exige que los miembros de la Junta tengan necesariamente especial preparación en materia de contratación pública. Pero su composición y organización queda relegada al reglamento.

EI DFJCP ha optado por una Junta de amplísima composición y representatividad que puede funcionar en Pleno y en Comisiones.

El Pleno de la Junta de Contratación Pública está formado por el Presidente, el Vicepresidente, el Secretario y catorce vocales. Estos vocales son designados por entidades representativas de intereses sociales (es la denominación utilizada por el art. 4.6 DFJCP).

Y aunque el Reglamento insiste en la determinación legal de que los miembros han de tener especial preparación en materia de contratación pública, es algo que queda confiado a los organismos que designan sin que exista ningún requisito mínimo sobre el tipo o la antigüedad de la profesionalidad de los designados, ni la obligación de acreditar ese conocimiento especial, ni ningún mínimo control del mismo.

En estas condiciones se habrá de aplicar la misma presunción que se hace sobre la valentía de los soldados de infantería: que por el hecho de ser designados como miembros de la Junta, la preparación especial en materia de contratación "se les supone"14.

En cualquier caso, y por lo que aquí nos atañe, no es el Pleno el que resuelve las reclamaciones en materia de contratación, sino que esta función es desempeñada

14 El TRLCSP sí establece unas mínimas condiciones sobre la titulación y profesionalidad tanto de los vocales, como del Presidente del Tribunal Administrativo Central de Recursos Contractuales (art. 41.1). 
exclusivamente por la Comisión Permanente de la Junta de Contratación Pública (arts. 3.2 y 25.1 DFJCP).

La Comisión Permanente está formada por el Vicepresidente de la Junta ${ }^{15}$, que será el Presidente de la Comisión, un Vocal designado por el Pleno entre sus miembros y el Secretario de la Junta ${ }^{16}$. Una persona adscrita al Servicio de Patrimonio del Departamento de Economía y Hacienda actuará como Secretario de la Comisión, sin voz y sin voto (art. 3.2 DFJCP).

\subsection{Legitimación de los reclamantes}

La reclamación en materia de contratación pública se podrá interponer "por las empresas y profesionales interesados en la licitación y adjudicación de un contrato público contra los actos de trámite o definitivos, que les excluyan de la licitación o perjudiquen sus expectativas" (art. 210.1 LFCP).

La acción de reclamación no es, por tanto, pública sino que requiere una especial relación con los actos que son objeto de reclamación. Una relación de la que pueden derivar perjuicios por resultar excluidos de la licitación o ver perjudicadas su expectativas $^{17}$. En definitiva, lo que se exige es que exista un interés en el asunto por parte de los reclamantes.

\section{Objeto: actos de la contratación pública impugnables}

De acuerdo con los objetivos comunitarios, la reclamación especial en materia de contratación es de carácter precontractual, es decir, se refiere a los actos que se producen en las fases de licitación y adjudicación.

En relación con los actos que se produzcan durante la ejecución del contrato, en uso de las clásicas prerrogativas contractuales de la Administración contratante, pueden ser objeto de los ordinarios recursos administrativos y contencioso-administrativos (art. 32.2 LFCP). Pero el sistema ordinario de recursos también será utilizable para los actos de licitación y adjudicación, ya que la reclamación especial es potestativa y no excluyente de otras reclamaciones o recursos (art. 210.5 LFCP).

15 El Vicepresidente de la Junta es el Director del Servicio de Patrimonio del Departamento de Economía y Hacienda (art. 4.4 DFJCP).

16 El Secretario de la Junta es el Jefe de la Sección de Contratación del Departamento de Economía y Hacienda (art. 4.4 DFJCP).

17 La redacción de este precepto se aleja de la terminología común sobre los interesados. Para empezar llama la atención que hable de "empresas y profesionales" y no simplemente de "personas". En cuanto a las "expectativas" que pueden verse perjudicadas, debe entenderse que son asimilables lo que técnicamente se denomina "intereses". Sobre esta cuestión es mucho más ortodoxa y técnicamente más correcta la redacción del artículo 42 del TRLCSP al regular la legitimación. 


\subsection{Contratación pública impugnable}

Las reclamaciones tienen como objeto la materia "contratación pública". Esa materia comprende todo tipo de contratos públicos. A diferencia del régimen comunitario, la reclamación podrá interponerse contra todos los contratos con independencia de que superen o no los umbrales comunitarios.

En segundo lugar, las reclamaciones podrán interponerse contra los contratos de todo tipo de poderes adjudicadores, pues como expresamente dice el artículo 210.1 LFCP, la reclamación se podrá referirse a contratos "dictados por una entidad sometida a la presente Ley Foral en un procedimiento de adjudicación, con las salvedades previstas en esta Ley Foral respecto al Parlamento de Navarra, las Entidades Locales de Navarra y la Universidad Pública de Navarra".

Las entidades sometidas a la LFCP son muy heterogéneas. En su ámbito de aplicación subjetivo se incluyen, además de las Administraciones públicas y sus organismos autónomos, el Parlamento de Navarra, la Cámara de Comptos y el Defensor del Pueblo de Navarra; así como las entidades públicas empresariales, sociedades mercantiles y laborales, fundaciones u otros entes vinculados o dependientes de las anteriores ${ }^{18}$. Incluso las personas y entidades privadas están sujetas a la ley cuando celebren determinados contratos administrativos, en lo relativo a la preparación y adjudicación de los contratos.

El artículo 210.1 establece, por tanto, una correlación entre el ámbito aplicativo de la LFCP y el ámbito de la reclamación de contratación pública, de manera que toda entidad adjudicadora de contratos está sometida al control que supone la reclamación especial en materia de contratación pública, incluidas las personas y entidades privadas $^{19}$.

\subsection{Actos impugnables}

Dentro de la amplia actividad de contratación pública, el tipo de actos impugnables por esta vía especial viene delimitado por dos factores:

18 Para estas últimas entidades se exige que cumplan conjuntamente los dos siguientes requisitos [art. 2.1, e) LFCP]:

“- Que en su actividad satisfagan, al menos parcialmente, fines de interés público que no tengan carácter industrial o mercantil.

- Que las Administraciones Públicas de Navarra financien, directa o indirectamente, más de la mitad de su actividad, o bien tengan influencia dominante sobre las mismas a través de mecanismos que controlen su gestión, o bien permitan designar a más de la mitad de los miembros de sus órganos de administración, de dirección o de vigilancia".

19 En cuanto a las salvedades a las que alude el artículo 210.1 se refieren a la posibilidad que se otorgaba tanto al Parlamento de Navarra, como a la Universidad Pública de Navarra de crear su propio órgano de resolución de las reclamaciones. Posibilidad de la que no hicieron uso en el plazo de tres meses que se les concedió (disp. adic. $13^{\mathrm{a}}$ ). La otra salvedad se refiere a las entidades locales que vieron reguladas las peculiaridades de su contratación adaptadas a la LFCP mediante la Ley Foral 1/2007, de 14 de febrero. 
a) Fase precontractual. La reclamación opera únicamente en la fase pre-contractual, es decir, en los actos relativos a "la licitación y adjudicación de un contrato público". Los actos relativos a la ejecución del contrato serán recurribles, como ya se ha dicho, a través del sistema ordinario de recursos (art. 32.2 LFCP).

La finalidad de la reclamación especial es establecer una vía rápida que impida la celebración de contratos litigiosos. De ahí que el sistema se complete con el establecimiento de un período intermedio entre la formalización del contrato y el inicio de su ejecución y la atribución a la Junta de Contratación Pública de la facultad de adoptar medidas cautelares.

La adjudicación se debe notificar a todos los interesados (art. 92.5 LFCP). Al no fijarse el plazo de la notificación se aplicará el de diez días hábiles establecido en la LRJPAC. Lo que sí se establece es un plazo de 15 días a partir de la notificación para la formalización del contrato (arts. 94.1 y 202.1 LFCP). Una formalización que es necesaria para dar inicio a la ejecución del contrato, salvo supuestos excepcionales de emergencia, contratos con tramitación de urgencia y procedimientos cuya única documentación exigible sea la factura (arts. 94.4, 202.2 LFCP). En el caso de la tramitación urgente se establece que se podrá acordar el comienzo de la ejecución del contrato antes de la formalización del mismo "una vez vencido el plazo de interposición de la reclamación ante la Junta de Contratación Pública”2o.

b) Actos de trámite o definitivos. En segundo lugar, la reclamación podrá tener por objeto "actos de trámite o definitivos, que les excluyan de la licitación o perjudiquen sus expectativas" (art. 210.1 LFCP).

No se especifica -como hace la LRJPAC o el TRLCSP21 - que los actos de trámite recurribles son los cualificados, es decir, los que deciden directa o indirectamente el fondo del asunto, determinan la imposibilidad de continuar el procedimiento o produzcan indefensión o perjuicio irreparable a derechos o intereses legítimos.

En la exposición de motivos de la LFCP sí se advierte que los actos de trámite "deben estar dotados de algún contenido relevante sin necesidad de que sean actos

20 Se ha criticado este sistema porque no garantiza que se cumpla la finalidad de evitar la formalización de contratos litigiosos. Ciertamente, es muy improbable que la reclamación se pueda resolver antes de la formalización del contrato e incluso antes del comienzo de su ejecución. A ello se une que la interposición de la reclamación no produce la suspensión automática de la ejecución, sino que es necesaria su solicitud y la resolución de la Junta de Contratación. Vázquez Matilla, F. J., "Comentario a la STJCE de 3 de abril de 2008. La vulneración de la Directiva sobre recursos y su incidencia en la normativa sobre contratación administrativa en Navarra", Revista Jurídica de Navarra, núm. 45, 2008, p. 173. Para superar esas dificultades propone utilizar el sistema de la adjudicación provisional y definitiva que estableció la LCSP y la suspensión automática de la formalización del contrato cuando hubiera sido objeto de una reclamación (pp.

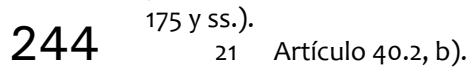


de trámite cualificados según los parámetros de la Ley Foral 15/2004 y de la Ley 30/1992". En cualquier caso, dado que en el articulado no se ha incorporado ninguna exigencia adicional sobre la cualificación o relevancia de los actos de trámite, cualquier acto no definitivo podrá ser recurrido sin que pueda ser inadmitido por dicho motivo.

\subsection{Motivos invocables}

La reclamación, además de tratarse de un recurso especial por razón de la materia, es un recurso extraordinario, ya que no es invocable cualquier ilegalidad, sino que sólo y exclusivamente se podrá fundar la reclamación en los motivos expresamente tipificados por la ley.

Si se apreciaran otros motivos de ilegalidad distintos podrán invocarse pero a través de los recursos ordinarios. En estos casos es compatible la interposición simultánea de ambos recursos, pues la incompatibilidad del recurso ordinario y la reclamación especial sólo se produce cuando concurre identidad del objeto, de los sujetos y también de las causas de la impugnación (art. 210.5, segundo párrafo LFCP) ${ }^{22}$.

Los motivos que se pueden esgrimir en la reclamación son tres (art. 210.3 LFCP):

“a) Encontrarse incurso el adjudicatario en alguna de las causas de exclusión de la licitación señaladas en esta Ley Foral.

b) La falta de solvencia económica y financiera, técnica o profesional del adjudicatario.

c) Las infracciones de las normas de publicidad, concurrencia y transparencia en la licitación o adjudicación del contrato y, en particular, de los criterios de adjudicación fijados y aplicados".

No es posible entrar en el análisis profundo y pormenorizado de cada uno de estos motivos. No obstante, cabe recordar dos cuestiones que habrán de tenerse en cuenta en la interpretación de dichos motivos. En primer lugar, que tratándose de unos motivos de carácter tasado y extraordinario su interpretación no puede ser extensiva, sino que habrá de ser restrictiva. En segundo lugar, debe tenerse en cuenta que dichos motivos se encuentran estrechamente vinculados a las fases precontractuales de la licitación y adjudicación, que son las directamente implicadas por la normativa contractual europea para garantizar la libre competencia y proscribir cualquier forma de discriminación.

22 Así lo ha advertido Razquin Lizarraga, J. A., “Las reclamaciones “, cit., p. 776. 


\section{Elemento conectivo o integrador: la reclamación como recurso potestativo y sustitutivo}

El elemento conectivo o integrador de una relación jurídica es el acaecimiento jurídicamente relevante que, bajo la forma de hecho, signo o acto jurídico integra los sujetos y el objeto en una totalidad organizada que es, precisamente, la relación jurídica²3.

En el caso de la relación jurídica de reclamación contractual ese acto que integra los sujetos y el objeto se produce con la presentación de la reclamación.

Interesa recordar, no obstante, que la integración de esta relación es potestativa para el reclamante. De manera explícita se señala el carácter potestativo y sustitutivo de la reclamación y que no impide la interposición de cuantas otras reclamaciones o recursos basados en otros motivos se interpongan ante otros órganos. Ahora bien, la interposición de una reclamación en materia de contratación pública impide la interposición de cualquier otro recurso administrativo basado en el mismo motivo (arts. 210. 5 LFCP y 25.2 DFJCP).

Está en la mano del reclamante, por tanto, escoger la vía que entienda más adecuada para la defensa de sus intereses frente a los actos de licitación y adjudicación. Eso sí, una vez que haya optado por la vía de la reclamación esa vía se convierte en excluyente de cualquier otro recurso administrativo fundado en el mismo motivo.

\section{ESTRUCTURA DINÁMICA: EL PROCEDIMIENTO DE RECLAMACIÓN}

La reclamación en materia contractual exige, para cumplir sus finalidades, un procedimiento ágil y sencillo. Este procedimiento se caracteriza por la brevedad de los plazos y la economización de trámites (por ejemplo, se prescinde de un trámite específico de prueba, aunque por otro lado, se introduce un preceptivo trámite de admisibilidad).

Su regulación legal y su desarrollo reglamentario son deliberadamente simples y se remiten para lo no previsto expresamente a las disposiciones en materia de recursos previstas en la legislación reguladora del procedimiento administrativo (arts. 210.6 LFCP y 25.4 DFJCP).

\section{Iniciación}

En la presentación de la reclamación se refleja el objetivo de la rapidez que se pretende lograr con este sistema de recurso especial. En comparación con los recursos administrativos ordinarios se va a establecer un plazo muy breve y su obligatoria presentación telemática.

23 González Navarro, F., Derecho administrativo español, cit., p. 289. 
El plazo de interposición de la reclamación es de "diez días, contados a partir del día siguiente, desde la notificación o publicación del acto impugnado" (art. 210.2 LF(P). Al no indicarse nada expresamente ha de entenderse que se trata de días naturales, de acuerdo con lo establecido en el artículo 26.1 de la propia LFCP. Y así lo ha establecido de manera expresa el artículo 29.1 del DFCP.

La presentación de la reclamación sólo se puede realizar "telemáticamente en el Portal de Contratación de Navarra ante la Junta de Contratación Pública”, debiéndose señalar una dirección de correo electrónico para la práctica de notificaciones (art. 212.1 LF(P) $)^{24}$.

En la reclamación deberán figurar los contenidos mínimos que son propios de los recursos administrativos (art. 110 LRJPAC). Pero, además, deberá contener la indicación del contrato de que se trate, el acto contra el que se reclama y los motivos de la reclamación, autenticándose mediante firma digital avanzada (art. 29.3 DFJCP).

Los efectos de la interposición son los comunes a la iniciación de los procedimientos y la imposibilidad de presentar otro recurso administrativo contra el mismo acto basado en el mismo motivo (art. 210.5 LFCP).

\section{Las medidas cautelares}

En el sistema de recursos contractuales, que se caracteriza por una especial preocupación por la celeridad y la eficacia, las medidas cautelares adquieren un gran protagonismo. Hasta el punto de que se configuran formalmente como una petición específica y separada de la reclamación. No obstante, aparece sustancialmente vinculada a la misma y con un carácter accesorio respecto de aquella.

En el mismo plazo que existe para presentar la reclamación (10 días naturales) "los interesados en la licitación y adjudicación de un contrato público podrán solicitar de la Junta de Contratación Pública además (...), la adopción de medidas cautelares” (art. 211.1).

Esa aparente independencia entre la reclamación y las medidas cautelares lo es solo en el plano formal, ya que "la solicitud y, en su caso, las propias medidas cautelares quedarán sin efecto si no se interpone la reclamación en el plazo previsto” (arts. 211.1 LFCP y 31.2 DFJCP).

Las medidas cautelares, en consecuencia, no tienen sustantividad propia y se extinguen si no hay una reclamación que las sustente. Llama por eso la atención que

24 A estos efectos, el DFJCP exige que el interesado esté en posesión de un Depósito Personal de Notificaciones, que será facilitado por la Junta de Contratación Pública. Es en ese Depósito donde se practicarán las notificaciones electrónicas (art. 29.2). 
ni la ley, ni el reglamento (que se limita a reproducir aquélla) no hayan contemplado la natural posibilidad de que se soliciten las medidas cautelares en el mismo escrito de interposición de la reclamación. Posibilidad que habrá de admitirse habida cuenta de la supletoriedad de la legislación sobre procedimiento administrativo y que, dada la identidad de plazos, en la práctica será lo normal25.

El objetivo de las medidas cautelares es garantizar la eficacia de la resolución futura de la reclamación. No es por ello muy acertada la finalidad que le asigna la ley cuando dice que las medidas cautelares se solicitan "para corregir la infracción alegada o para impedir que se causen otros perjuicios a los intereses afectados, incluidas la suspensión de cualquier decisión adoptada en el seno del procedimiento de adjudicación o del procedimiento mismo" (art. 211.1 LFCP). La corrección de la infracción se producirá con la anulación declarada por la resolución de la reclamación. Lo que sí pueden lograr las medidas cautelares es impedir que se causen perjuicios innecesarios hasta que se produzca la resolución de la reclamación y para ello la medida más adecuada será la suspensión del acto recurrido. De todas formas, aunque la suspensión es la única medida expresamente mencionada, en virtud de la aplicación supletoria del procedimiento administrativo ordinario, se podrá adoptar cualquier medida que resulte adecuada -y proporcionada- para asegurar la eficacia de la resolución futura.

La tramitación del "incidente" cautelar es muy sencilla (arts. 211.2 LFCP y 32 DFJCP):

- Presentación telemática en el Portal de Contratación de Navarra ante la Junta de Contratación Pública.

- Requerimiento a la entidad contratante del expediente administrativo o documentación del contrato que deberá aportar en el plazo de dos días hábiles. A diferencia del procedimiento de reclamación, no se prevé la audiencia a terceros interesados.

- Transcurrido dicho plazo, se haya aportado o no la documentación requerida, la Junta de Contratación Pública resolverá motivadamente, en el plazo de cinco días hábiles. La notificación de la resolución se realizará telemáticamente ${ }^{26}$.

No se establecen los criterios que deben utilizarse para acordar -o denegar- la adopción de medidas cautelares, por lo que serán aplicables los establecidos en la regulación de los recursos ordinarios. Lo mismo cabe decir de la prestación de caución o garantía para responder de los perjuicios que pudieran derivarse de la adopción de medidas cautelares. La normativa navarra -a diferencia de la estatal27 - no la

25 Así lo ha afirmado Razquin Lizarraga, J. A., “Las reclamaciones “, cit., p. 785. $\begin{array}{lll}268 & 26 & \text { Esta previsión que no estaba en la LFCP, fue establecida por el DFJCP (art. 32.1, último inciso). } \\ & 27 & \text { Artículo 43.3 TRLCSP. }\end{array}$ 
prevé expresamente, pero será exigible en virtud de las disposiciones generales reguladoras del procedimiento administrativo.

Si no se resuelve en el plazo establecido, se entenderá resuelta la petición por silencio administrativo. Éste tiene distinto sentido según haya sido la petición: silencio negativo como regla general, salvo que se hubiera solicitado la suspensión de un acto o del procedimiento de licitación, en cuyo caso la falta de notificación en plazo tendrá carácter estimatorio (art. 211.2 LFCP). Con esta excepción -que en la práctica será la más habitual, puesto que la medida cautelar más típica será la petición de suspensión- se respeta la regla del silencio positivo establecido con carácter general en el artículo 111.3 LRJPAC.

Frente a la resolución sobre las medidas cautelares no cabrá recurso, sin perjuicio de los que procedan contra las resoluciones que se dicten en el procedimiento principal (art. 211.3 LFCP). No es nada claro el sentido de este precepto. En mi opinión, la resolución de las medidas cautelares no es impugnable autónomamente, aunque cabrá el posterior planteamiento de nuevas medidas cautelares en el recurso que pueda interponerse contra la resolución de la reclamación que, como luego se verá, será el contencioso-administrativo, dado que dicha resolución pone fin a la vía administrativa.

Acordadas las medidas cautelares, éstas podrán ser suspendidas, modificadas o revocadas en cualquier momento, de oficio o a solicitud de parte interesada, en virtud de circunstancias sobrevenidas o que no pudieron ser conocidas al tiempo de su adopción (art. 211.3 LFCP). A estas medidas cautelares no se les puede aplicar la regla general (art. 111.4 LRJPAC) de la posible prolongación de su eficacia hasta el pronunciamiento judicial sobre la medida cautelar, puesto que la Junta de Contratación Pública ya no interviene tras su resolución de la reclamación, puesto que la ejecución de ésta corresponde, como se verá, a la entidad contratante ${ }^{28}$.

\section{Desarrollo o instrucción}

La instrucción o desarrollo del procedimiento de reclamación también se contagia de la celeridad que se pretende dar a esta vía. Tan solo se prevén tres únicos trámites con plazos brevísimos. A diferencia de la legislación estatal no se prevé la apertura de un específico trámite de prueba ${ }^{29}$, sin perjuicio de la que puedan aportar los sujetos que intervengan en el procedimiento.

\subsection{Trámite de admisión de la reclamación (y eventual subsanación)}

Pese al objetivo de instaurar un procedimiento ágil y rápido, la LFCP prevé como primera decisión tras la presentación de la reclamación el estudio de su admisión a

28 Razquin Lizarraga, J. A., “Las reclamaciones...”, cit., p. 787.

29 Artículo 46.4 TRLCSP. 
trámite. Es una decisión preceptiva, no facultativa como en el proceso contenciosoadministrativo ${ }^{30}$. Se establece con carácter imperativo: "recibida la reclamación, la Junta de Contratación Pública resolverá sobre la admisión a trámite en el plazo de tres días hábiles" (art. 212.2).

No obstante, si se aprecia que la reclamación es incompleta se deberá otorgar al reclamante un plazo de subsanación de dos días hábiles.

Las causas de inadmisión de la reclamación son cinco (arts. 212.2 LFCP y 29.6 DFJ(P):
“a) La interposición extemporánea.
b) La falta de legitimación del reclamante.
c) La falta de subsanación de la solicitud.
d) La falta de competencia de la Junta de Contratación Pública.
e) La carencia manifiesta de fundamento".

Las dos primeras causas de inadmisión se refieren a la carencia de los requisitos temporales y subjetivos de la reclamación y no presentan particularidades dignas de mención. La tercera causa constituye una alteración de lo establecido con carácter general en la LRJPAC, que considera la falta de subsanación de la solicitud como un supuesto de desistimiento (art. 70). En cualquier caso, figura como causa de inadmisión y así se está aplicando en la práctica31.

La falta de competencia de la Junta de Contratación Pública ha sido la causa de inadmisión más frecuente en las reclamaciones presentadas hasta el momento. Puede comprender varias situaciones ${ }^{32}$ : la impugnación de un acto en materia contractual que no puede ser objeto de la reclamación especial33; la alegación de motivos distintos a los invocables en la reclamación ${ }^{34}$; y la presentación de una reclamación cuando se ha interpuesto también un recurso administrativo ordinario por idéntico motivo.

El quinto motivo es el más indeterminado tanto en su sustancia (la ausencia de fundamento), como en su grado (la carencia ha de ser manifiesta) 35 .

La interpretación de estos motivos de inadmisión habrá de ser restrictiva por el carácter tasado y excepcional de los mismos y por poner fin anticipadamente a la re-

30 Así lo ha advertido Razquin Lizarraga, J. A., “Las reclamaciones “, cit., p. 780.

31 Hasta agosto de 2008, ha habido ocho inadmisiones de las reclamaciones por esta causa.

32 Razquin Lizarraga, J. A., “Las reclamaciones...”, cit., p. 780.

33 Según los datos que ofrece la Junta de Contratación Pública en el Portal de Contratación de Navarra, de las 38 inadmisiones que se han acordado 26 han sido por esta causa.

34 En 6 ocasiones se ha resuelto inadmitir las reclamaciones por la alegación de motivos no tasados.

35 Sobre este supuesto se ha dicho que se puede equiparar al previsto en la LJCA relativo a la inadmisión del recurso contencioso-administrativo cuando se hubieren desestimado en el fondo recursos sustancialmente iguales por sentencia firme, mencionando en este caso, la resolución o resoluciones desestimatorias (Razquin Lizarraga, J. A., “Las reclamaciones “, cit., p. 779). 
clamación y adoptarse sin audiencia de las partes. Además, la admisión a trámite de la reclamación no impediría que en la resolución final se entendiera que concurre una causa de inadmisión para acordar su desestimación ${ }^{36}$.

EI DFJCP ha atribuido la competencia sobre la resolución de este trámite al Secretario de la Junta de Contratación (art. 29.5). A mi juicio esta atribución resulta completamente inadecuada. Salvo la carencia de la subsanación de la solicitud -y, en algunos casos, la presentación extemporánea de la reclamación- los motivos de inadmisión requieren de una interpretación de las circunstancias fácticas y jurídicas que debieran ser objeto de análisis por el órgano competente para resolver las reclamaciones (la Comisión Permanente de la Junta). Téngase en cuenta que la inadmisión pone fin anticipadamente a la reclamación y, además, pone fin a la vía administrativa, por lo que no resulta apropiado que se haga residir la competencia en un órgano unipersonal como el Secretario del órgano colegiado competente para la resolución.

Los requisitos temporales y formales de la resolución de este trámite son los siguientes. El plazo de resolución es de tres días hábiles. No se especifica en el Reglamento si el plazo es solo de resolución o también de notificación. Dada la brevedad del plazo habrá que entender que, contrariamente a la regla general establecida en la LRJPAC, será sólo de resolución. Tampoco se dice nada sobre la falta de resolución en plazo. Dado que la regla general del silencio administrativo es el sentido estimatorio y dada la necesidad de justificar el motivo de inadmisión, hay que entender que el silencio es estimatorio y, en consecuencia, se deberá entender que la resolución es admitida a trámite ${ }^{37}$.

La resolución de este trámite se notificará al reclamante tanto si es de inadmisión (art. 212.2 LFCP), como si se admite la reclamación (art. 212.3 LFCP). Evidentemente, la de inadmisión deberá estar fundada y motivar la concurrencia de alguna de las causas de inadmisión. Cabe adelantar que el plazo establecido para la resolución del procedimiento de reclamación se anuda a este acuerdo de admisión, lo que refuerza la necesidad de la resolución expresa y su notificación.

La resolución pone fin a la vía administrativa (art. 212.2 LFCP), por lo que contra ella no cabrá ningún otro recurso administrativo [art. 109, b) LRJPAC] y sólo podrá impugnarse en vía contencioso-administrativa.

\subsection{Reclamación del expediente y contestación a la reclamación por la entidad recurrida}

Admitida a trámite la reclamación, la Junta de Contratación Pública -a través de su Secretario ${ }^{38}$ - interesará de la entidad afectada la remisión del expediente adminis-

36 En este mismo sentido se ha manifestado Razquin Lizarraga, J. A., “Las reclamaciones...", cit., p. 781.

37 En el mismo sentido, Razquin Lizarraga, J. A., “Las reclamaciones...”, cit., p. 780.

38 Artículo 29.7 DFJCP. 
trativo o de la documentación del contrato, adjuntando a la notificación una copia de la reclamación (arts. 212.3 LFCP y 29.7 DFJCP).

La entidad recurrida deberá aportar de forma telemática y en el plazo de tres días hábiles el expediente administrativo o la documentación del contrato, junto con la contestación a la reclamación.

Mucha es la confianza del legislador en el cumplimiento de este deber, puesto que no prevé las consecuencias de su incumplimiento, ni de la paralización del procedimiento que se producirá si no se produce la remisión del expediente.

\subsection{Audiencia a los interesados}

Recibido el expediente administrativo o la documentación del contrato ${ }^{39}$, la reclamación se notificará a los demás interesados para que en el plazo de tres días hábiles aporten las alegaciones o pruebas que estimen oportunas (art. 212.3 LFCP).

La comunicación a los terceros interesados se hará, como todas los trámites, telemáticamente. Y si no disponen de una cuenta de correo electrónico, la LFCP prevé que será suficiente el emplazamiento en el Portal de Contratación de Navarra.

\section{Terminación}

El procedimiento de reclamación podrá terminar mediante las diferentes formas de terminación anormal (desistimiento, renuncia, caducidad) reguladas en la LRJPAC, aunque la LFCP solo regula la resolución.

\subsection{Plazo de la resolución y silencio negativo}

La resolución que decida la reclamación se deberá dictar en el plazo de veinte días hábiles desde la admisión a trámite de la misma ${ }^{40}$.

Sumando la duración máxima de todos los trámites, la firmeza -por esta vía de reclamación especial, sin perjuicio de los recursos ordinarios y contenciosos que pudieran interponerse- de los actos de licitación y adjudicación se alcanza aproximadamente en mes y medio. Se conceden 10 días naturales para la interponer la reclama-

39 El DFJCP establece que transcurrido dicho plazo "incluso si no se ha remitido el expediente" la reclamación se notificará a los terceros interesados para que formulen las alegaciones o pruebas que estimen necesarias. Parece difícil que la audiencia se pueda practicar sin poder consultar el expediente, por lo que entiendo que los terceros interesados podrán esperar a tener el expediente para formular sus alegaciones.

40 Esos 20 días se contarán, como precisa el DFJCP, a partir del día siguiente a aquel en el que se produzca la admisión a trámite (art. 30.1). 
ción y ésta deberá estar resuelta como máximo en 29 días hábiles (tres días hábiles para la admisión a trámite; tres días hábiles para la remisión del expediente y la contestación a la reclamación; otros tres días hábiles para la audiencia de los terceros interesados; y 20 días hábiles para dictar y notificar la resolución).

Transcurrido el plazo de los veinte días hábiles sin que se haya notificado la resolución expresa se entenderá desestimada la reclamación (art. 213.1 LFCP). Además, la resolución de la reclamación se publicará en el Portal de Contratación de Navarra (art. 30.1).

Establecer como día inicial del plazo de resolución la admisión a trámite de la reclamación puede plantear el problema de que no exista dies a quo. Para el caso de que no se produzca formalmente la admisión a trámite (que, como se ha visto, debe darse tanto si se inadmite como si se admite) ni la LFCP, ni su reglamento de desarrollo han establecido un plazo supletorio para que se produzca el acto ficticio por silencio. La única solución será acudir al plazo supletorio de tres meses establecido en la LRJPAC.

En cuanto al sentido del silencio, se sigue la regla general del silencio negativo en los procedimientos de impugnación (art. 43.2 LRJPAC). También se sigue el criterio general de que el plazo establecido lo es no solo para la resolución, sino también para la notificación.

Debe, por ello, hacerse una interpretación correctora de lo dispuesto en el DFJCP. Éste dispone que la reclamación se dictará y se entregará en el Depósito Personal de Notificaciones (art. 30). Pero el depósito telemático de la resolución no equivale necesariamente a la notificación, ya que ésta no se produce hasta su lectura o hasta que trasncurran 10 días desde el depósito. Por ello, resulta más acertada la previsión legal de anudar los efectos desestimatorios a la notificación, que cuando es electrónica no equivale al envío de la misma.

\subsection{Criterios y contenido de la resolución}

La resolución habrá de ser motivada y congruente con la petición. Podrá tener un sentido estimatorio o desestimatorio de la reclamación. De manera expresa, se exige que la resolución decida sobre la anulación de las decisiones ilegales adoptadas durante el procedimiento de adjudicación, incluyendo la supresión de las características técnicas, económicas o financieras discriminatorias contenidas en el anuncio de licitación, anuncio periódico indicativo, pliegos de cláusulas administrativas y de prescripciones técnicas particulares, condiciones reguladoras del contrato o cualquier otro documento relacionado con la licitación o adjudicación (arts. 213.2 LFCP y 30.2 DFJCP).

Dos cuestiones se plantean sobre el alcance de las facultades decisorias de la Junta ${ }^{41}$. En primer lugar, si la congruencia se limita a la pretensión del reclamante o si,

41 Las dos han sido planteadas por Razquin Lizarraga, J. A., “Las reclamaciones...”, cit., pp. 782 y 783. 
dado el carácter limitado y especial de esta reclamación, puede decidir sobre otras cuestiones conexas que se planteen en el procedimiento, aunque no hubieran sido alegadas por el reclamante, en este caso debiendo conceder al reclamante audiencia tal y como establece la LRJPAC (art. 113.3).

En segundo lugar, las facultades de la Junta se limitan a enjuiciar la validez de los actos administrativos recurridos, sin que puedan ejercerse pretensiones sobre el restablecimiento de situaciones jurídicas individualizadas, ni siquiera la de solicitar indemnización por daños y perjuicios, si bien será difícil que estos se produzcan por la rapidez que es consustancial a esta vía ${ }^{42}$.

Lo que sí parece razonable es que la resolución se pronuncie sobre el levantamiento de la suspensión y de las medidas cautelares, tal y como expresamente se reconoce en el TRLCSP (art. 47.4).

\subsection{Eficacia de la resolución}

\section{A) Fin de la vía administrativa y ejecutividad}

Las resoluciones de la Junta de Contratación Pública ponen fin a la vía administrativa y son inmediatamente ejecutivas y vinculantes, correspondiendo a la entidad promotora de la licitación la inmediata ejecución de las mismas (arts. 210.4 LFCP y 28 DFJCP).

Al igual que las resoluciones de alzada, las resoluciones de las reclamaciones en materia de contratación pública ponen fin a la vía administrativa y contra ellas podrá interponerse el correspondiente recurso contencioso-administrativo ${ }^{43}$. $Y$ al igual que todos los actos administrativos, las resoluciones son inmediatamente ejecutivas y vinculantes. No estamos ante simples dictámenes o recomendaciones, sino ante auténticas resoluciones ejecutivas.

Eso sí, la ejecución no corresponde a la Junta de Contratación Pública sino a la entidad promotora de la licitación. Es más, la Junta no dispone de mecanismos para la ejecución forzosa, ni para vencer eventuales resistencias de la entidad licitadora al cumplimiento de sus reclamaciones.

\section{B) Indemnización por sustitución de la resolución estimatoria}

Como se ha visto, el enjuiciamiento de la legalidad de los actos recurridos se atribuye a la Junta de Contratación, pero la ejecución de sus resoluciones correspon-

42 Esta posibilidad sí está expresamente prevista en el TRLCSP (art. 47.3). También se prevé la posibilidad de imponer multas si se aprecia temeridad o mala fe en la interposición del recurso o en la solicitud de medidas cautelares (art. 47.5).

43 Esta posibilidad está expresamente prevista en el TRLCSP, el cual también establece la imposi-

254 bilidad de la revisión de oficio de la resolución del recurso (art. 49.1). 
de a la entidad promotora de la licitación. Esa ejecución deberá realizarse, como es obvio, en los términos previstos en ella. No obstante, se prevé un supuesto en el que se admite la sustitución de la ejecución de la resolución de la reclamación por una indemnización compensatoria.

Este supuesto excepcional de sustitución de la ejecución de la resolución estimatoria de la reclamación requiere la concurrencia de dos presupuestos (art. 213.3 LFCP):

- Que, a pesar de la celeridad de esta vía de reclamación, se haya iniciado la ejecución del contrato.

- Que existan razones técnicas o de equidad que hagan desaconsejable dejar sin efecto la adjudicación. Este segundo requisito, al hacerse depender de conceptos jurídicos indeterminados, requerirá de un mayor esfuerzo justificativo por parte de la entidad contratante.

Se fijan también los criterios para determinar la cuantía de la indemnización: ésta “deberá tener en cuenta la posibilidad real de que el reclamante hubiera obtenido la adjudicación de no haber mediado la infracción y deberá cubrir, al menos, los gastos ocasionados por la preparación de la oferta o la participación en el procedimiento de licitación" (art. 213.3 LFCP).

Sorprendentemente ni la ley, ni el reglamento establecen el procedimiento para acordar esta sustitución de la ejecución de la reclamación. Nótese que la Junta de Contratación ya no interviene ni en la decisión de la sustitución, ni en la determinación de la indemnización. Pero es evidente que, cuando menos, la decisión deberá adoptarse oyendo previamente a los interesados sobre los dos aspectos: el acuerdo de sustitución y la fijación de la indemnización. La terminación convencional resultará especialmente adecuada para resolver este procedimiento.

\section{DIFERENCIAS PRINCIPALES ENTRE LA REGULACIÓN NAVARRA Y LA LEGISLACIÓN ESTATAL DE CONTRATOS PÚBLICOS}

A modo de epílogo o resumen de lo dicho, puede resultar útil la comparación entre el sistema navarro de reclamación en materia de contratación y el recurso especial en materia de contratación regulado en el TRLCSP.

A mi juicio, las principales diferencias que apreciar entre los dos regímenes son las siguientes.

\section{1. Órgano competente para resolver el recurso especial en materia contractual}

Las dos normativas optan por instituir un recurso especial cuya resolución se atribuye a un órgano administrativo especializado y distinto al contratante. Ahora 
bien, mientras en Navarra la resolución se atribuye a la Junta de Contratación Pública que tiene además otras funciones consultivas y asesoras (art. 208 LFCP); en la normativa estatal se distinguen ambos tipos de funciones y se crea el Tribunal Administrativo Central de Recursos Contractuales (art. 42 TRLCSP), manteniéndose como órgano consultivo la Junta Consultiva de Contratación Administrativa del Estado (art. 324 TRLCSP).

\section{Diferencias en cuanto al objeto del recurso}

Dos diferencias sustanciales cabe apreciar en cuanto a la materia objeto de recurso.

$1^{\mathrm{a}}$ ) En Navarra la reclamación contractual se generaliza y es aplicable a todos los contratos públicos sometidos al ámbito de aplicación de la LFCP sin referencia a umbrales comunitarios. En cambio, en la legislación estatal se limita a los contratos armonizados (art. 40.1 TRLCSP).

$2^{a}$ ) Los actos recurribles según el TRLCSP son los actos de trámite cualificados (art. 40.2, b), mientras que en la legislación navarra son impugnables todo tipo de actos de trámite (art. 210.1 LFCP).

\section{Diferencias en cuanto al carácter extraordinario del recurso}

Tras su última modificación la ley estatal confiere al recurso, como ya había hecho la legislación navarra, un carácter potestativo y sustitutivo (arts. 210.5 LFCP y 40.6 TRLCSP).

Ahora bien, mientras el recurso especial de la legislación estatal puede fundarse en cualquier infracción del ordenamiento jurídico, en la LFCP se limitan las causas de ilegalidad invocables en la reclamación (art. 210.3). Eso convierte a la reclamación en un recurso de carácter extraordinario. Eso sí, para las ilegalidades no incluidas entre los motivos de la reclamación se admite que se utilicen los recursos ordinarios (art. 210.5).

\section{Procedimiento de reclamación telemático}

Todos los trámites de la reclamación especial en materia contractual de Navarra se realizan telemáticamente a través del Portal de Contratación de Navarra. En la legislación estatal, en cambio, se siguen utilizando los medios ordinarios de presentación escrita de la reclamación en los registros administrativos bien del órgano 


\section{Diferencias en la iniciación del procedimiento de recursos y en sus efectos}

Dos diferencias son apreciables en este ámbito:

$\left.1^{\mathrm{a}}\right)$ El TRLSCP exige el anuncio previo de la interposición del recurso y su interposición en el plazo de 15 días hábiles (art. 44), mientras que la legislación navarra no exige el anuncio previo y el plazo de interposición es de 10 días naturales (art. 210.2 LFCP).

$2^{\mathrm{a}}$ ) En el TRLSCP cuando el acto recurrido es de adjudicación quedará en suspenso la tramitación del expediente de contratación (art. 46), mientras que en Navarra la suspensión deberá ser solicitada y acordada por la Junta de Contratación Pública.

\section{Diferencias en la tramitación o instrucción del procedimiento}

En los trámites comunes se aprecian diferencias de plazos, siendo en casi todos los casos más breves los de la legislación navarra:

- Para la subsanación se establecen 2 días hábiles en Navarra y 3 días hábiles en la legislación estatal;

- Para la remisión del expediente y la contestación a la reclamación se establecen 3 días hábiles en Navarra y 2 días hábiles en la legislación estatal;

- Tres días hábiles para las alegaciones de los interesados en Navarra, frente a los cinco días hábiles en el TRLCSP;

- Posibilidad de apertura de un período de prueba por diez días hábiles en la legislación estatal, mientras que en Navarra no se prevé dicha posibilidad.

Pero la diferencia más significativa es que en Navarra se establece un preceptivo trámite de admisibilidad de la reclamación que no se prevé en la legislación estatal.

\section{Diferencias en la resolución del procedimiento}

Dos diferencias importantes se aprecia en la regulación de la resolución:

$\left.1^{a}\right)$ El contenido de la resolución del recurso estatal puede ser más rico y variado que el previsto en la legislación navarra. EI TRLCSP prevé que se pueda acordar el levantamiento de la suspensión y de las medidas cautelares y, sobre todo, admite que se incluya la determinación de los daños y perjuicios 
causados. Además también puede imponer sanciones en caso de apreciar temeridad o mala fe en el recurrente (art. 47).

$2^{\mathrm{a}}$ ) En la legislación estatal no se establece el sentido del silencio, ni se establece un plazo específico de resolución, por lo que será aplicable lo previsto en la LRJPAC: plazo de tres meses y sentido desestimatorio del silencio. En la LFCP se establece un plazo máximo de 20 días hábiles desde la admisión a trámite de la resolución y se establece expresamente el sentido negativo del silencio. 